\title{
Effectiveness of fetal ultrasound diagnostics in cardiac malformations and association with polyhydramnios and oligohydramnios
}

\author{
Atene Simonyi ${ }^{1}$, Fanni Rebeka Eros ${ }^{1}$, Julia Hajdu ${ }^{1,2}$, Artur Beke ${ }^{1}$ \\ ${ }^{1}$ Department of Obstetrics and Gynecology, Semmelweis University, Budapest, Hungary; ${ }^{2}$ Gottsegen György Hungarian Institute of Cardiology, \\ Budapest, Hungary
}

Correspondence to: Artur Beke, MD, PhD, MedHabil. Department of Obstetrics and Gynecology, Semmelweis University, 1088 Budapest, Baross u. 27., Hungary. Email: beke.artur@med.semmelweis-univ.hu.

Background: Examine the effectiveness of prenatal ultrasound diagnostics in the detection of cardiovascular malformations, and their association with polyhydramnios and oligohydramnios.

Methods: We examined the fetal ultrasonography and postnatal clinical/fetopathological data of 372 newborns/fetuses over a 7-year period in a tertiary centre. Fetal echocardiography was performed in cases of suspected US findings between 18-32 weeks. During the ultrasound the amniotic fluid amount was measured and the amniotic fluid index (AFI) or largest amniotic fluid pocket was determined.

Results: Prenatal ultrasonographic results and postnatal/fetopathological diagnosis were fully congruent in $236 / 372$ cases (63.4\%), and in 66/372 cases of cardiovascular anomalies (17.7\%) the discovery was partial, while in 70/372 cases no fetal cardiovascular anomalies were diagnosed during pregnancy (18.8\%) (false negative). Cardiovascular malformations were isolated in 255 cases, in 172 of which $(67.5 \%)$ the results of prenatal ultrasonography and postnatal diagnostics were fully congruent. In 43 cases (16.9\%) the prenatal discovery was partial, and in 40 cases $(15.7 \%)$ there was no prenatal recognition of the malformation. Cardiovascular abnormalities were found as a part of multiple malformations in 76 cases. In 41 fetuses the cardiovascular malformation was associated with chromosomal abnormalities. Cardiovascular malformations were significantly associated with polyhydramnios. Although in some of the cardiovascular malformations the association rate with polyhydramnios was high (AVSD, double outlet right ventricle, tetralogy of Fallot), we found a moderate association rate (19.7\%). The association with oligohydramnios was $8.57 \%$.

Conclusions: Echocardiography plays an important role in the prenatal diagnostics. In cases of polyhydramnios and oligohydramnios, fetal echocardiography should be performed.

Keywords: Cardiovascular abnormality; effectiveness of ultrasonography; polyhydramnios; oligohydramnios

Submitted Jul 01, 2020. Accepted for publication Mar 17, 2021.

doi: 10.21037/qims-20-823

View this article at: http://dx.doi.org/10.21037/qims-20-823

\section{Introduction}

Prevalence rates of major congenital fetal malformations is around $2-3 \%$ based on the literature (1-4). The most common cases are the cardiovascular abnormalities, their prevalence at birth is $0.7-0.9 \%$, and about in half of these cases there is a major, life-threatening defect present (5-8). The cardiovascular malformations are often associated with abnormalities of other organ systems $(9,10)$. The birth prevalence of cardiac malformations in the EUROCAT study was 6.4/1,000 (https://eu-rd-platform.jrc.ec.europa. eu/eurocat/eurocat-data/prevalence) (1).

Screening for congenital malformations is carried out by prenatal ultrasound scans. The efficiency of the detection of cardiovascular differences is affected by the complexity 
of the deviation, the investigator's experience, the type of the ultrasound machine, or the thickness of the maternal abdominal wall (11-13). Fetal echocardiography is the most widely used method for the accurate detection of cardiac malformations. The effectiveness of the ultrasonography in the diagnosis of these variations shows a significant difference in different studies (20-68\%) (14-24).

Several objective methods can be used to characterize the amount of amniotic fluid. One method is the AFI (amniotic fluid index) measured with the four-quadrant technique. To calculate this, the maximum vertical thickness of the amniotic fluid in four quadrants of the uterus should be added up and measured in centimetres. Its normal value is $5-24 \mathrm{~cm}$. The other method is the single deepest pocket technique, determining the vertical diameter of the deepest pocket of amniotic fluid. Its normal value is $2-8 \mathrm{~cm}(25-28)$.

The objective of our study is (I) to examine the effectiveness of prenatal ultrasonographic diagnosis in detecting congenital cardiac malformations and (II) to investigate the proportion of the cardiac malformations associated with polyhydramnios or oligohydramnios.

\section{Methods}

In a prospective study we have processed the fetopathological or postnatal records with cardiovascular malformations diagnosed at the 1st Department of Obstetrics and Gynaecology over a 7-year period between 2009 and 2015 . Prenatal ultrasound findings, postnatal clinical data and fetopathological findings were processed. We involved in the study all patients who had delivery or abortion (spontaneous and TOP) with newborns/fetuses with diagnosis of cardiovascular malformation. We excluded all patients who had no ultrasound during pregnancy. Postnatally detailed echocardiography was performed, and in cases of fetal or postnatal death or abortion fetopathological investigation was performed.

We have introduced the "Partially Recognized" category to characterize these cases. Those cases were considered partially recognized where the abnormality of the particular organ was detected during the ultrasound examination, but the final diagnosis was different on the basis of the examinations performed after birth/abortion, compared to the presumed diagnosis. For the purpose of statistical processing, as a correct diagnosis was made during the ultrasound examination performed during pregnancy — even if not the first time the organ system disorder arose- these cases were classified into the "Totally Recognized" category.
Our Genetic Center and Ultrasound Laboratory is a referral Fetal Medicine Unit to which pregnant women with suspected fetal abnormality are referred to. Fetal echocardiography was performed in cases of suspected US findings between 18-32 weeks. In cases of any maternal and familiar indications (cardiac malformations in the family, maternal diabetes mellitus, gestational diabetes, maternal fever, virus infection, maternal rubella infection, maternal alcoholism, maternal drug/medical exposition (e.g., lithium), maternal lupus erythematodes, maternal PKU) or fetal indications (polyhydramnios, oligohydramnios, small for gestational age, twin pregnancies, non-immune hydrops, nuchal translucency/thickening, cystic hygroma, fetal arrhythmias, other extracardiac abnormalities, chromosome abnormalities) the echocardiography was performed between 18-22 weeks.

The sonographic examinations were conducted according to the professional protocols elaborated by the Hungarian Society of Obstetric and Gynaecological Ultrasonography (Fetal echocardiography, 10/02/2003; Recommended ultrasound examination during pregnancy, 10/02/2003, http://www.msznut.hu/protokollok.aspx, 2003). The fetal heart can be represented in specific planes: (I) we can see in the "four-chamber plane" the right and left ventricles, atria, mitral and tricuspid valves, ventricular and atrial septum, foramen ovale, pulmonary veins, pericardium, ventricular and atrial walls; (II) a "five-chamber plane" allows us the visualization of the left ventricular outflow; (III) the "right ventricular outflow" shows the right ventricle, pulmonary valves, pulmonary artery, ductus arteriosus, aortic arch detail; (IV) the next plane is the "aortic arch" by visualization of the aorta and ductus arteriosus; (V) after the visualization of pulmonary veins; (VI) color Doppler can be used to examine the valves and the integrity of the ventricular septum.

The sonographic examinations were performed in the Ultrasound Laboratory of the 1st Department of Obstetrics and Gynaecology using Philips ${ }^{\circledR}$ HD 11XE (Philips Ultrasound), GE Voluson ${ }^{\circledR}$ 730PRO (GE Medical System Kretztechnik GmbH \& Co OHG) and Medison SA9900 ultrasound devices (Medison Co., LTD). All the fetal echocardiographies were performed by one examiner, using GE Voluson 730PRO ultrasound.

Postnatally in each case the same paediatric cardiologist performed the postnatal echocardiography and in serious cases there were CTA or operation, and in cases of postnatal death the pathological findings give us the correct postnatal diagnosis. In cases of termination, accurate fetopathology provide the correct diagnosis. 


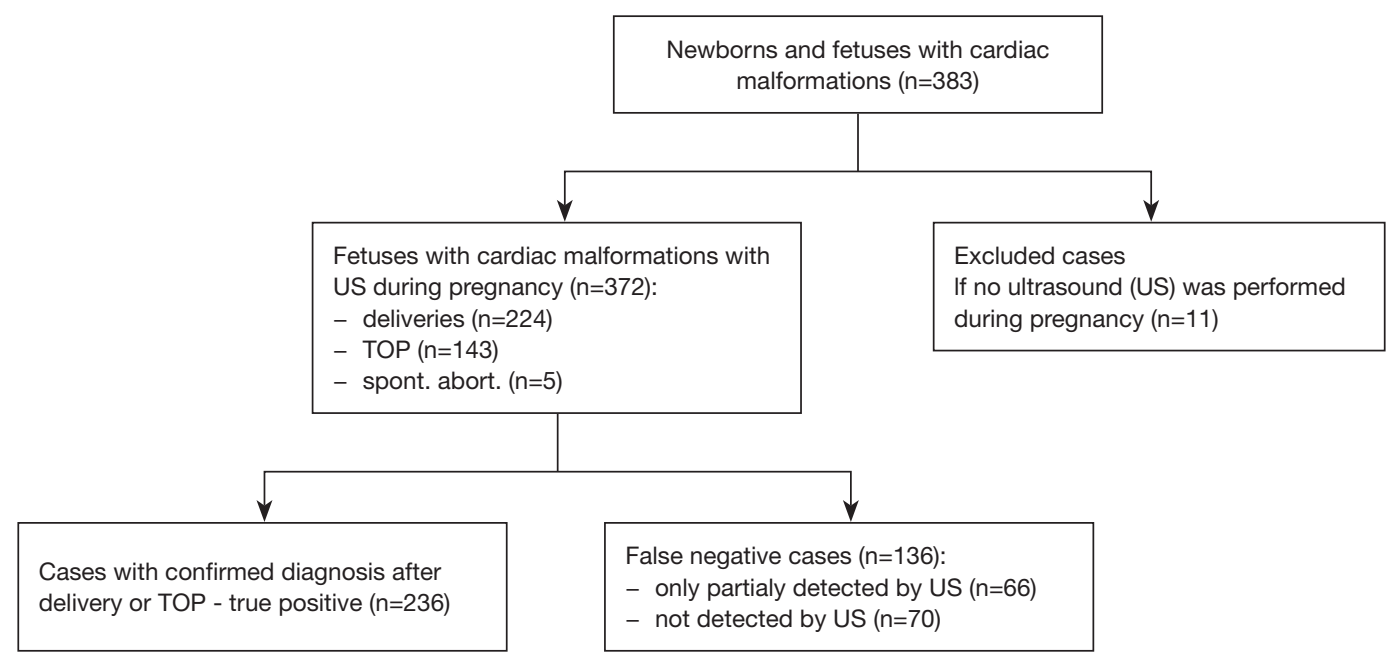

Figure 1 Flow diagram of the study selection process.

Table 1 Accuracy of prenatal detection of cardiac malformations ( $N=372$ fetuses)

\begin{tabular}{lcccc}
\hline Type of abnormalities & Total number & Totally recognized, $\mathrm{n}(\%)$ & Partially recognized, $\mathrm{n}(\%)$ & Not recognized, $\mathrm{n}(\%)$ \\
\hline Isolated cardiac abnormalities & 255 & $172(67.5)$ & $43(16.9)$ & $7(17.1)$ \\
Associated with chromosome abnormalities & 41 & $26(63.4)$ & $16(21.1)$ & $8(19.5)$ \\
Part of multiple malformation & 76 & $38(50.0)$ & $66(17.7)$ & $7(28.9)$ \\
Total & 372 & $236(63.4)$ & $(18.8)$ \\
\hline
\end{tabular}

Our work complies with the principles of the Declaration of Helsinki, and approved by the Ethics Committee of the Institution (Scientific Research Ethics Committee permission number: SE-TUKEB 231). Subjects gave written informed consent to our work.

In statistical procession calculating significance the Chisquare test was used. In the case of $\mathrm{P}<0.05$, the anomaly was considered as statistically significant.

For the characterization of the association rate of polyhydramnios or oligohydramnios occurring in certain fetal anatomical malformations, the following categories were determined: the association rate was low if $<10 \%$. We classified it as moderate category if the rate was between $\geq 10 \%-<25 \%$. The association rate was classified as high between $\geq 25 \%$ and $<50 \%$ and it was considered extremely high in case of $\geq 50 \%$.

\section{Results}

During the 7-year period, there were 25,700 deliveries, 321 spontaneous midtrimester abortions, and 806 midtrimester terminations (TOP) with fetal malformation. During the 7-year period a total of 372 fetuses had some kind of abnormality of the heart (Figure 1). In 224 out of 372 cases the pregnancy ended in childbirth, while in 148 cases abortion occurred. In 5 cases spontaneous miscarriage occurred, and the abortion was induced in cases of 143 fetuses. In 255 out of 372 fetuses the cardiovascular malformation occurred isolated, in 41 cases associated with chromosomal abnormalities, and in 76 cases appeared as part of a multiple malformation (Table 1). In cases of examined fetuses, prenatal ultrasonographic diagnosis and postnatal/fetopathological results fully coincided in $236 / 372$ cases $(63.4 \%)$, in 66/372 cases $(17.7 \%)$ the detection was partial, and in $70 / 372$ patients no malformations were found during pregnancy (18.8\%) (false negative cases) (Table 1). In addition to the 372 fetuses with cardiovascular malformations, there were an additional 22 who were assumed to have a cardiovascular malformation by ultrasound examination, which could not be documented after birth (false positive cases).

In 255 cases the cardiovascular malformation was not associated with disorders of any other organ, the results 
of prenatal sonography tests and postnatal/post abortion examinations completely coincided in 172 fetuses (67.5\%), in 43 cases $(16.9 \%)$ the prenatal discovery was partial, while in 40 cases $(15.7 \%)$ no malformation was detected prenatally.

The cardiovascular abnormality appeared as part of a multiple malformation in 76 cases, in 38 fetuses $(50 \%)$ there was complete coincidence between the prenatal diagnosis and the postnatal/post abortion findings, in 16 cases the match was partial $(21.1 \%)$, while in 22 fetuses $(28.9 \%)$ no cardiac malformation was detected. In 42 out of 76 cases the number of affected organ systems was 2 , and in 34 cases the number of affected organ systems was $\geq 3$. The associated anomalies were most commonly abdominal and abdominal wall defects (29 cases), urogenital and craniospinal abnormalities (27 cases respectively), malformations of the extremities ( 21 cases), and craniofacial malformations (20 cases) were also detected. In 6 cases thoracic disorders, while in 2 cases fetal hydrops have occurred.

In 20 out of 41 cases of chromosome disorders trisomy 21 (Down syndrome), 15 cases of trisomy 18 (Edwards syndrome) and 2 cases of trisomy 13 (Patau syndrome) have occurred. In 4 cases other chromosomal abnormalities were reported: 2 triploidy cases, one case of ring formation of the $\mathrm{X}$ chromosome, and one case of trisomy 9 . In 26 out of 41 fetuses $(63.4 \%)$ the prenatal ultrasonography fully detected the cardiac malformations, in 7 cases the discovery was partial $(17.1 \%)$, and in 8 cases no malformation was recognized (19.5\%).

Among the 372 fetuses with cardiac abnormalities, 346 fetuses were from single pregnancies, 24 fetuses from twin pregnancies, and 2 fetuses from trigeminal pregnancies. In two cases of the twin pregnancies, we detected cardiac abnormalities in both of the twins. In one case in fetus A there was situs inversus totalis, while in fetus B there was ASD and complete transposition of the great vessels present. In the other case fetus A had AVSD and pulmonary stenosis, and in fetus B tetralogy of Fallot and pulmonary atresia have occurred.

A total of 607 cardiovascular malformations were detected in the 372 fetuses (Table 2). Table 3 shows the positive predictive value, negative predictive value, sensitivity, and specificity, of detection in all groups. Out of the 607 cardiovascular malformations 421 has been completely detected antenatally $(69.36 \%)$, while 92 cases partially $(15.16 \%)$, and 94 cases $(15.49 \%)$ not at all; 57 cases were included in the group of other cardiac disorders (Table 4).

We examined the association of polyhydramnios and oligohydramnios with all cardiovascular malformations. Polyhydramnios occurred in $19.77 \%$ of the cases, while oligohydramnios in $8.57 \%$ of the cases (Table 5). Table 5 shows how often each malformation occurred associated with the quantitative difference of the amniotic fluid. Among cardiovascular malformations, the association rate with polyhydramnios was high ( $\geq 25 \%$ to $<50 \%$ ) in cases of atrioventricular septal defect (AVSD), double outlet right ventricle, tetralogy of Fallot, dilated right heart, dilated right and left ventricle, situs inversus, heart aneurysm and pericardial effusion. Extremely high $(\geq 50 \%)$ association rate with polyhydramnios was found in cases of right dyslocated heart. In contrast to polyhydramnios, cardiac malformations were associated with oligohydramnios at a lower rate, we could not detect any high association rates. The difference was significant in favour of polyhydramnios against oligohydramnios in cases of ventricular septal defect, atrioventricular septal defect, univentricular heart, aortic atresia, double outlet right ventricle and other malformations of the heart.

\section{Discussion}

In our study, the birth prevalence of cardiac malformations was $14.36 / 1,000$. This exceeded the data of van der Linde et al. (found in Europe, 8.2/1,000) and the data of 7.8/1,000 found by Chew et al., and 9.7/1,000 found by Ngeow et al., and it was significantly higher than the results of the EUROCAT study $(6.4 / 1,000)$ and of Levi et al. $(6.2 / 1,000)(1,6,8,15,22)$. If we only examine the deliveries, the prevalence of the cardiovascular malformations is 8.72/1,000, exceeding the data of Eleftheriades et al. $(7.2 / 1,000)(17)$. Our data were similar to the closer central European Czech Republic data published in 2010. The total data of 1,472,610 live births were analysed between the 1994-2008 period. Congenital malformations of the circulatory system present more than $40 \%$ of all registered congenital anomalies and they are the most frequent birth defect group in births in the Czech Republic. As a whole, 29,133 CHD were diagnosed (19.783 per 1,000 live births) in 18,811 children (12.753 per 1,000 live births) (18).

The higher birth prevalence measured in our Department can be partly caused by the fact, that this is a central patient care clinic, so we meet proportionally more disorders than an average hospital. Our Department operates as a prenatal diagnostic tertiary center, pregnant women are referred to our clinic from many parts of the country to be examined and consulted in progressive patient care. In the course of our 
Table 2 Evaluating the effectiveness of fetal ultrasound diagnostics in cardiac malformations in different cardiac malformations (N=607)

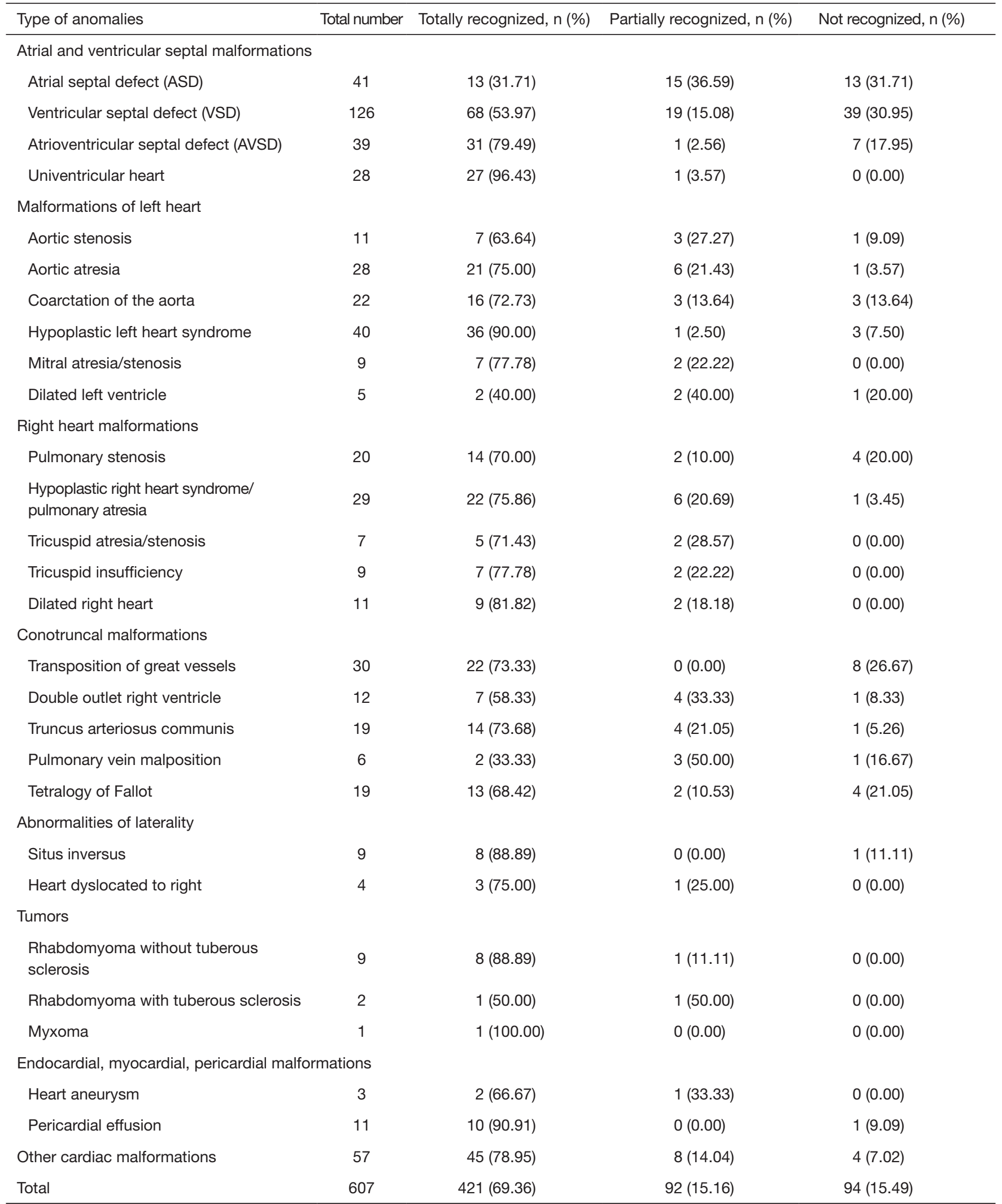




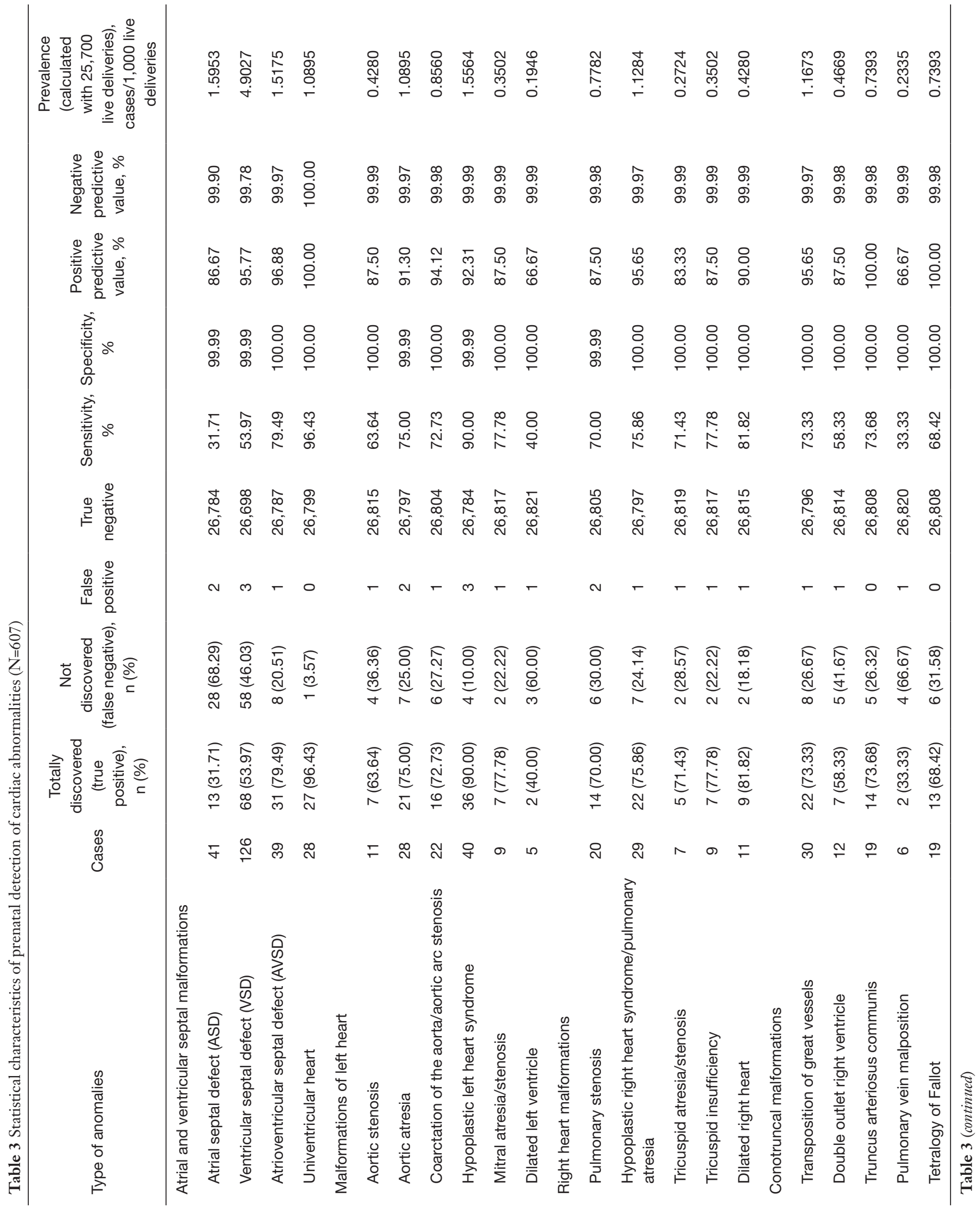




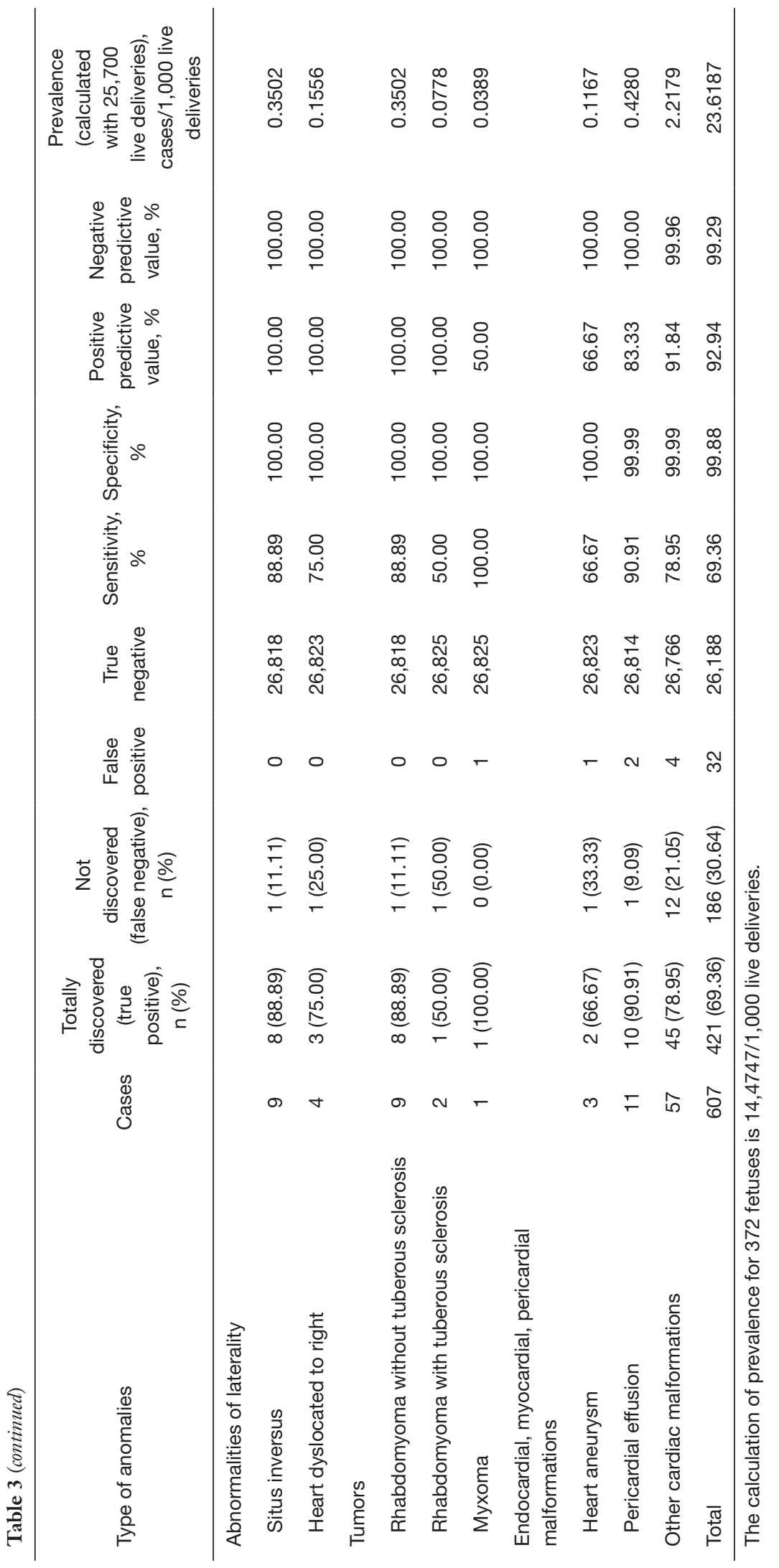


Table 4 Other cardiac malformations

\begin{tabular}{lc}
\hline Type of abnormalities & Total $\mathrm{n}=57$ \\
\hline Endocardial fibroelastosis & 16 \\
Cardiomegaly & 6 \\
Other complex cardiac malformation & 8 \\
Ectopia cordis & 4 \\
Dilated left ventricle & 2 \\
Ebstein anomaly & 2 \\
Aortic arch interruption & 3 \\
Mitral insufficiency & 2 \\
Atrial dilatation & 1 \\
Persistent left subclavian vein & 1 \\
Atresia ostii dextri cordis & 1 \\
Acarida & 1 \\
Fibrosis myocardial calcification & 1 \\
Pericardial teratoma & 1 \\
Right aortic arch & 1 \\
Inferior vena cava dilatation & 1 \\
Intracardial teratoma & 1 \\
Subclavian artery abnormally & 1 \\
Persistent left superior vena cava & 1 \\
Tricuspid valve dysplasia & 1 \\
\hline Atrioventricular valve hypoplasia & 1 \\
\hline
\end{tabular}

work, besides other counseling situations, genetic counseling is often encountered with ultrasonic malformations detected in the intrauterine fetus. These differences may include: (I) differences detected in ultrasound examinations performed at other institutes, and confirmed by our Genetic Counseling's ultrasound examination, performed at our clinic; (II) differences detected by ultrasonography during routine pregnancy care at our clinic, and these cases referred to the Genetic Counseling; (III) due to other reasons (e.g., due to differences in biochemical parameters), cases referred to our Genetic Counseling, and the abnormalities were detected by our ultrasound examination; (IV) differences detected during fetal echocardiography for other maternal and fetal reasons.

The sensitivity rate of prenatal ultrasound diagnostics was $67.5 \%$, if the cardiovascular malformation was not associated with other organ system differences. The result was similar to Liu review (68.1\%) (23). If other organ systems were involved, there was a much lower sensitivity rate of $50 \%$. Klein et al. reached the opposite result: in their case study they could prenatally detect multiple malformations in $47.7 \%$, while if only the cardiovascular malformations were present, the sensitivity rate was $25.5 \%$ (20). Our results are explained by that in cases where other major organ system abnormalities were present, milder variations of the heart (ASD in 6 cases) were not diagnosed.

The number of true negative cases was high, because of that in all cardiac malformations the negative predictive value was high. The positive predictive values were high in all cases of cardiac malformations, because of low rate of false positive cases.

Forty-one fetuses $(10.17 \%)$ had chromosome abnormalities, in 20 cases trisomy 21 , in 15 cases trisomy 18, in 2 cases trisomy 13 , in 4 cases other differences. Paladini et al. found chromosome abnormalities in 15 of 31 fetuses with cardiac malformations (48\%), in 6 cases trisomy 21, in 4 cases trisomy 18 , in 4 cases trisomy 13 and triploidy in one case (21).

In our study, in cases of cardiovascular malformations, polyhydramnios occurred cumulatively in $19.77 \%$, which can be considered as moderate. In contrast, cardiac malformations were highly associated with polyhydramnios in some cases. Such malformations were: atrioventricular septal defect $(30.77 \%)$, double outlet right ventricle (41.67\%), tetralogy of Fallot (47.37\%). In cases of dilated left ventricle, situs inversus and heart aneurysm we found also higher rate of polyhydramnios, but the case number was $<10$, so the statistical analysis was not relevant.

The limitation of the study was that there were 21 cases with positive ultrasound findings about cardiac malformations, but after the ultrasound exam we have no information about the pregnancy.

\section{Conclusions}

Postnatally and prenatally diagnosed cardiac malformations coincided in high rate of the cases $(69.36 \%)$. According to our results, ultrasonographic examination and fetal echocardiography play a significant role in diagnosing cardiovascular malformations but they do not always detect all disorders. It is important to know which malformations can be detected prenatally with a high certainty, and which anomalies can only be diagnosed partially or not at all before birth. High expectations of the parents, that all anomalies can be fully detected antenatally may lead to 
Table 5 Polyhydramnios and oligohydramnios were observed in fetuses with cardiac malformations

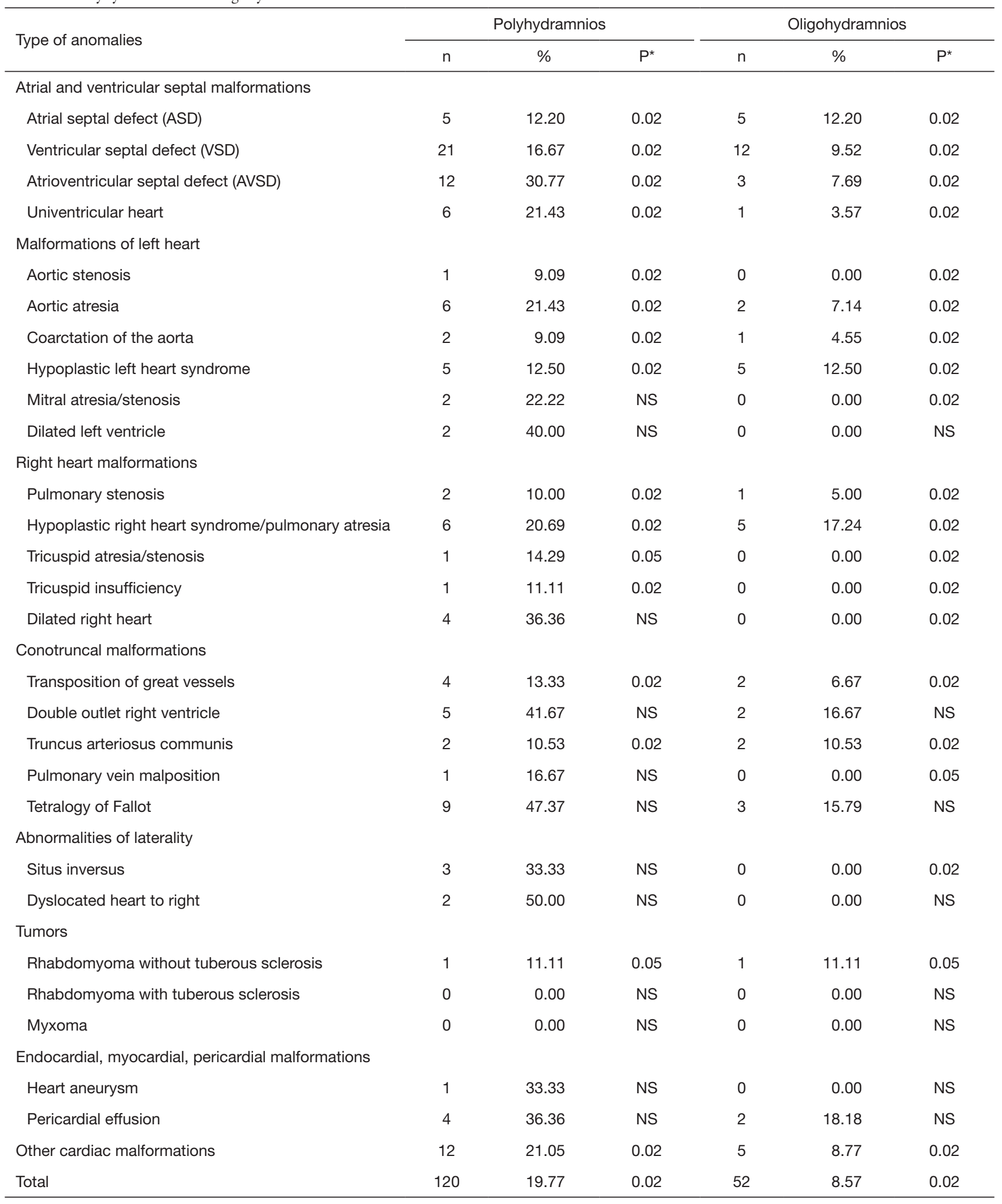

*, in relation to the occurrence of average amount of amniotic fluid. 
lawsuits in undiagnosed cases. Thus, it is indispensable for physicians to be up-to-date in the efficacy of obstetric ultrasound to be able to inform the parents properly. It is also important for physicians to know the association rate of cardiac malformations with oligohydramnios/ polyhydramnios.

\section{Acknowledgments}

The authors are also thankful to Kutasi Aniko and Glovocz Bea genetic assistants for their valuable technical help. Funding: None.

\section{Footnote}

Conflicts of Interest: All authors have completed the ICMJE uniform disclosure form (available at http://dx.doi. org/10.21037/qims-20-823). The authors have no conflicts of interest to declare.

Ethical Statement: Our work complies with the principles laid down in the Declaration of Helsinki. The work has been approved by the Ethics Committee of the Semmelweis University (Scientific Research Ethics Committee permission number: SE-TUKEB 231). Subjects gave written informed consent to our work.

Open Access Statement: This is an Open Access article distributed in accordance with the Creative Commons Attribution-NonCommercial-NoDerivs 4.0 International License (CC BY-NC-ND 4.0), which permits the noncommercial replication and distribution of the article with the strict proviso that no changes or edits are made and the original work is properly cited (including links to both the formal publication through the relevant DOI and the license). See: https://creativecommons.org/licenses/by-nc-nd/4.0/.

\section{References}

1. Boyd PA, Haeusler M, Barisic I, Loane M, Garne E, Dolk H. Paper 1: The EUROCAT Network-Organization and Processes. Birth Defects Res A Clin Mol Teratol 2011;91 Suppl 1:S2-15.

2. Levi S. Ultrasound in prenatal diagnosis: polemics around routine ultrasound screening for second trimester fetal malformations. Prenat Diagn 2002;22:285-95.

3. Fadda GM, Capobianco G, Balata A, Litta P, Ambrosini G, D'Antona D, Cosmi E, Dessole S. Routine second trimester ultrasound screening for prenatal detection of fetal malformations in Sassari University Hospital, Italy: 23 years of experience in 42,256 pregnancies. Eur J Obstet Gynecol Reprod Biol 2009;144:110-4.

4. VanDorsten JP, Hulsey TC, Newman RB, Menard MK. Fetal anomaly detection by second-trimester ultrasonography in a tertiary center. Am J Obstet Gynecol 1998;178:742-9.

5. Hoffman JI. Incidence of congenital heart disease: II. Prenatal incidence. Pediatr Cardiol 1995;16:155-65.

6. Chew C, Halliday JL, Riley MM, Penny DJ. Populationbased study of antenatal detection of congenital heart disease by ultrasound examination. Ultrasound Obstet Gynecol 2007;29:619-24.

7. Westin M, Saltvedt S, Bergman G, Kublickas M, Almström H, Grunewald C, Valentin L. Routine ultrasound examination at 12 or 18 gestational weeks for prenatal detection of major congenital heart malformations? A randomized controlled trial comprising 36299 fetuses. BJOG 2006;113:675-82.

8. van der Linde D, Konings EEM, Slager MA, Witsenburg M, Helbing WA, Takkenberg JJM, Roos-Hesselink JW. Birth Prevalence of Congenital Heart Disease Worldwide. J Am Coll Cardiol 2011;58:2241-7.

9. Smythe JF, Copel JA, Kleinman CS. Outcome of prenatally detected cardiac malformations. Am J Cardiol 1992;69:1471-4.

10. Boldt T, Andersson S, Eronen M. Outcome of structural heart disease diagnosed in utero. Scand Cardiovasc J 2002;36:73-9.

11. DeVore GR, Medearis AL, Bear MB, Horenstein J, Platt LD. Fetal echocardiography: factors that influence imaging of the fetal heart during the second trimester of pregnancy. J Ultrasound Med 1993;12:659-63.

12. Wong SF, Chan FY, Cincotta R, Lee-Tannock A, Ward C. Factors influencing the prenatal detection of structural congenital heart diseases. Ultrasound Obstet Gynecol 2003;21:19-25.

13. Srinivasan S. Fetal echocardiography. Ind J Pediatr 2000;67:20-5.

14. Friedberg MK, Silverman NH, Moon-Grady AJ, Tong E, Nourse J, Sorenson B, Lee J, Hornberger LK. Prenatal Detection of Congenital Heart Disease. J Pediatr 2009;155:26-31.

15. Levi S, Hyjazi Y, Schaapst JP, Defoort P, Coulon R, Buekens P. Sensitivity and specificity of routine antenatal screening for congenital anomalies by ultrasound: the Belgian Multicentric Study. Ultrasound Obstet Gynecol 
1991;1:102-10.

16. Stoll C, Dott B, Alembik Y, De Geeter B. Evaluation and evolution during time of prenatal diagnosis of congenital heart diseases by routine fetal ultrasonographic examination. Ann Genet 2002;45:21-7.

17. Eleftheriades M, Tsapakis E, Sotiriadis A, Manolakos E, Hassiakos D, Botsis D. Detection of congenital heart defects throughout pregnancy, impact of first trimester ultrasound screening for cardiac abnormalities. J Matern Fetal Neonatal Med 2012;25:2546-50.

18. Sípek A, Gregor V, Sípek A Jr, Hudáková J, Horácek J, Klaschka J, Skibová J, Langhammer P, Petrzílková L, Klímová B, Perinová B, Wiesnerová J. Incidence of congenital heart defects in the Czech Republic--current data. Ceska Gynekol 2010;75:221-42.

19. Marek J, Tomek V, Skovranek J, Povysilova J, Samanek M. Prenatal ultrasound screening of congenital heart disease in an unselected national population: a 21-year experience. Heart 2011;97:124-30.

20. Klein SK, Cans C, Robert E, Jouk PS. Efficacy of routine fetal ultrasound screening for congenital heart disease in Isere county, France. Prenat Diagn 1999;19:318-22.

21. Paladini D, Calabro L, Palmieri S, D’Andrea T. Prenatal diagnosis of congenital heart disease and fetal karyotyping. Obstet Gynecol 1993;81:679-82.

22. Ngeow AJ, Tan MG, Choo JT, Tan TH, Tan WC, Chan

Cite this article as: Simonyi A, Eros FR, Hajdu J, Beke A. Effectiveness of fetal ultrasound diagnostics in cardiac malformations and association with polyhydramnios and oligohydramnios. Quant Imaging Med Surg 2021;11(7):2994-3004. doi: 10.21037/qims-20-823
DK. Screening for congenital heart disease in a Singapore neonatal unit. Singapore Med J 2019. doi: 10.11622/ smedj.2019167. [Epub ahead of print].

23. Liu H, Zhou J, Feng QL, Gu HT, Wan G, Zhang HM, Xie YJ, Li XS. Fetal echocardiography for congenital heart disease diagnosis: a meta-analysis, power analysis and missing data analysis. Eur J Prev Cardiol 2015;22:1531-47.

24. Ghi T, Dall'Asta A, Cavalli C, Galli L, Weiss A, Pedrazzi G, Kaihura CT, Volpe N, Agnetti A, Frusca T. How often an isolated cardiac disproportion predicts a coarctation of the aorta? Single center experience and systematic review of the literature. J Matern Fetal Neonatal Med 2018;31:1350-7.

25. Dashe JS, McIntire DD, Ramus RM, Santos-Ramos R, Twickler DM. Hydramnios: anomaly prevalence and sonographic detection. Obstet Gynecol 2002;100:134-9.

26. Pauer HU, Viereck V, Krauss V, Osmers R, Krauss $\mathrm{T}$. Incidence of fetal malformations in pregnancies complicated by oligo- and polyhydramnios. Arch Gynecol Obstet 2003;268:52-6.

27. Biggio JR Jr, Wenstrom KD, Dubard MB, Cliver SP. Hydramnios prediction of adverse perinatal outcome. Obstet Gynecol 1999;94:773-7.

28. Zhang J, Troendle J, Meikle S, Klebanoff MA, Rayburn WF. Isolated oligohydramnios are not associated with adverse perinatal outcomes. BJOG 2004;111:220-5. 